\title{
Investigating Physical Chromatin Associations Across the Xenopus Genome by Chromatin Immunoprecipitation
}

\author{
George E. Gentsch ${ }^{1,2}$ and James C. Smith ${ }^{1,2}$ \\ ${ }^{1}$ Division of Systems Biology, National Institute for Medical Research, London NW7 1AA, United Kingdom
}

Chromatin immunoprecipitation (ChIP) combined with genomic analysis techniques provide a global snapshot of protein-DNA interactions in the context of chromatin, yielding insights into which genomic loci might be regulated by the DNA-associated protein under investigation. This protocol describes how to perform ChIP on intact or dissected Xenopus embryos. The ChIP-isolated DNA fragments are suitable for high-throughput sequencing (ChIP-Seq) or for quantitative PCR (ChIPqPCR). In this protocol, embryonic tissue is harvested from Xenopus tropicalis or Xenopus laevis at the developmental stage of interest, and DNA-associated proteins are immobilized to their endogenous genomic binding sites with formaldehyde. Nuclei are extracted from embryos and subjected to sonication so as to shear the chromatin to a size that allows sufficient positional resolution of protein binding to genomic DNA. Chromatin fragments bound by the protein of interest are immunoprecipitated using antibody-coupled beads, washed under high-stringency conditions, and stripped from the beads with anionic detergents. The chemical cross-links are reversed, and the coimmunoprecipitated DNA is purified. The resulting DNA fragments can be analyzed by qPCR or used to create a ChIP-Seq library. General advice for qPCR and for making ChIP-Seq libraries is offered, and approaches for analyzing ChIP-Seq data are outlined.

It is essential that you consult the appropriate Material Safety Data Sheets and your institution's Environmental Health and Safety Office for proper handling of equipment and hazardous materials used in this protocol.

RECIPES: Please see the end of this protocol for recipes indicated by $<R>$. Additional recipes can be found online at http://cshprotocols.cshlp.org/site/recipes.

Reagents

Agarose gel (1.4\%) and reagents for electrophoresis (see Step 27)

Amphibian medium appropriate for Xenopus species of interest (see Step 1.iii)

Marc's Modified Ringer's (MMR) for Xenopus ChIP $<\mathrm{R}>$

Normal amphibian medium $(\mathrm{NAM})<\mathrm{R}>$

ChIP-grade antibody (see Steps 5-8)

Dithiothreitol (DTT)

Dynabeads blocking buffer (phosphate-buffered saline A (PBS[A]) $<\mathrm{R}>$ containing $0.1 \%$ bovine serum albumin [BSA; Sigma-Aldrich A3059])

E1 buffer for ChIP $<\mathrm{R}>$

\footnotetext{
${ }^{2}$ Correspondence: ggentsc@nimr.mrc.ac.uk, director@nimr.mrc.ac.uk

(c) 2014 Cold Spring Harbor Laboratory Press

Cite this protocol as Cold Spring Harb Protoc; doi:10.1101/pdb.prot080614
} 
G.E. Gentsch and J.C. Smith

E2 buffer for ChIP $<$ R $>$

E3 buffer for ChIP $<$ R $>$

Formaldehyde solution (36.5\%-38\%; Sigma-Aldrich F8775)

Use the solution within $1 \mathrm{wk}$ after opening the bottle.

HEG solution (optional; see Step 4) $<\mathrm{R}>$

Immunoglobulin (Ig) control (e.g., Santa-Cruz sc-2025 and sc-2027; see Steps 5-8)

Liquid nitrogen

Magnetic beads (see Steps 5-8)

Dynabeads M-280 sheep anti-mouse IgG (Invitrogen 11201D)

Dynabeads M-280 sheep anti-rabbit IgG (Invitrogen 11203D)

Dynabeads Protein A (Invitrogen 10001D)

Dynabeads Protein G (Invitrogen 10004D)

$\mathrm{NaCl}(5 \mathrm{M})$

$\mathrm{NaF}(0.5 \mathrm{M})$

$\mathrm{Na}_{3} \mathrm{VO}_{4}(0.1 \mathrm{M})$

Phenylmethylsulfonyl fluoride (PMSF) (Sigma-Aldrich P7626)

Protease inhibitor tablets (complete, EDTA-free, Roche 11836170001[Mini] or 05892953001[Ultra])

Proteinase K (Ambion AM2548)

QIAquick PCR Purification Kit (QIAGEN)

Buffer EB, provided with the kit, is the same as $10 \mathrm{~mm}$ Tris ( $\mathrm{pH} 8.5$ ).

Qubit Fluorimeter reagents (Invitrogen Q32851) (optional; see Step 46)

Reagents for phenol:chloroform:isoamyl alcohol purification and ethanol precipitation of DNA (optional; see Step 45):

Ethanol $(80 \%, 100 \%)$

GlycoBlue (Ambion AM9516)

Phenol:chloroform:isoamyl alcohol (25:24:1; pH 7.9) (Ambion AM9730)

Sodium acetate (3 $\mathrm{M}, \mathrm{pH}$ 5.2)

Water (molecular grade)

RIPA buffer for Xenopus ChIP $<\mathrm{R}>$

RNase A (Invitrogen 12091-039)

SDS elution buffer $<\mathrm{R}>$

TE buffer (10 mm Tris [pH 8.0] and 1 mm EDTA)

TEN buffer for ChIP $<\mathrm{R}>$

Triton X-100 (10\%)

Wash solutions for beads (optional; see Step 32)

High-salt solution buffer $<\mathrm{R}>$

$\mathrm{LiCl}$ solution buffer $<\mathrm{R}>$

Low-salt solution buffer $<\mathrm{R}>$

Xenopus embryos (see Step 1)

\section{Equipment}

Conical tubes $(15 \mathrm{~mL}, 50 \mathrm{~mL})$

Laboratory (support) jack (e.g., Edu-Lab CH0642)

Magnetic rack (Dynal) for microcentrifuge tubes for bead separation (Invitrogen)

Microcentrifuge tubes $(1.5 \mathrm{~mL}, 2 \mathrm{~mL})$

Siliconized low-retention 1.5-mL microcentrifuge tubes (Ambion AM12450) are required for several steps in the protocol.

Oven (e.g., Techne Hybridizer HB-1D) for incubations at $37^{\circ} \mathrm{C}, 55^{\circ} \mathrm{C}$, and $65^{\circ} \mathrm{C}$ 


\section{Cross-Linking Proteins to Their Endogenous DNA Binding Sites}

1. Prepare the embryos.

i. Consult Table 1 to estimate the number of embryos required to perform your ChIP experiment.

Currently, 5-10 million cells expressing the DNA-associated protein of interest are required to create a ChIP-Seq library. For example, at late gastrula stage (Stage 12), 200 embryos with $\sim 40,000$ cells each may be enough if the protein is ubiquitously expressed. More embryos are needed accordingly for locally expressed proteins. ChIP-qPCR experiments require only a fraction of these quantities (e.g., $\sim 100,000-500,000$ cells expressing the protein of interest). At gastrula stage, 50 to 100 embryos are generally enough for most ChIP-qPCR experiments assuming that some proteins of interest are only expressed in small parts (up to 1/40th) of the embryo. These empirical numbers may change with varying antibody quality, cross-linking efficiency, and epitope accessibility. See Discussion.

ii. Harvest dejellied Xenopus embryos, or parts of them, at the developmental stage of interest. Embryos can be harvested and dejellied according to Sive et al. (2007).

iii. Transfer the embryos to a scintillation glass vial and wash them once in the appropriate amphibian medium.

We use $0.01 \times$ MMR for Xenopus tropicalis embryos or $0.1 \times$ NAM for Xenopus laevis.

2. Fix whole embryos by adding formaldehyde to a final concentration of $1 \%$ in the appropriate amphibian medium (e.g., $260 \mu \mathrm{L}$ formaldehyde solution [36.5\%-38\%] in $9 \mathrm{~mL}$ amphibian

TABLE 1. Number of cells per embryo during early Xenopus development

\begin{tabular}{lc}
\hline Developmental stage $^{a}$ & Number of cells per embryo $^{\mathbf{b}}$ \\
\hline 4 & 8 \\
6 & 32 \\
7.5 & 256 \\
8 & $\sim 1000$ \\
8.5 & $\sim 4000$ \\
10 & $\sim 30,000$ \\
12 & $\sim 40,000$ \\
19 & $\sim 90,000$ \\
32 & $\sim 200,000$ \\
\hline
\end{tabular}

${ }^{a}$ According to Nieuwkoop and Faber (1994).

${ }^{\mathrm{b}}$ From Woodland and Gurdon (1968) and Dale and Slack (1987). 
G.E. Gentsch and J.C. Smith

medium). Incubate the embryos in the fixative at room temperature for 20-25 $\min$ (X. tropicalis) or 30-35 $\min$ (X. laevis).

The appropriate fixation time to immobilize proteins on DNA must be determined empirically and varies according to frog species, developmental stage, DNA binding properties, and antibody epitope. The indicated time range is a good starting point for fixing gastrula-stage embryos. Embryos of later stages or dissected parts are normally fixed for a shorter time, such as $15 \mathrm{~min}$ (X. tropicalis) or 20-25 min (X. laevis) for late neurula/early tailbud embryos. Xenopus laevis embryos are fixed longer because of their bigger size. See Discussion.

3. Remove the fixative by quickly washing embryonic tissue three times with the appropriate icecold amphibian medium.

This inconspicuous washing step is key for extracting nuclei from cross-linked tissue and then efficiently shearing chromatin (see Discussion). At this stage, embryos are very fragile and should not come into contact with the liquid surface.

These fixed embryos can be used immediately (see Step 10); alternatively, they can be frozen and stored for later use as described in Step 4.

4. (Optional) Freeze and store the embryos as follows.

i. Carefully transfer the embryonic tissue (e.g., groups of 250 embryos or fewer) into prechilled $2-\mathrm{mL}$ microcentrifuge tubes. Remove as much remaining medium as possible from the embryos.

ii. Add approximately one volume (equivalent to the volume of embryonic tissue) of ice-cold HEG solution.

iii. Allow the embryos to settle to the bottom of the tube and remove the excess HEG.

iv. Snap-freeze the embryos in liquid nitrogen and store at $-80^{\circ} \mathrm{C}$ for future use.

\section{Coupling ChIP-Grade Antibody to Magnetic Beads}

At least 1 h before immunoprecipitation (Step 31), magnetic beads of the appropriate type (usually anti-lgG or protein $A / G)$ are blocked and coupled to a ChIP-grade antibody. Use the following guidelines as a starting point for $\mathrm{X}$. tropicalis embryos. For ChIP-qPCR experiments, nonspecific Ig of the antibody isotype are also coupled to the beads to be used as a control.

5. Transfer the required volume of resuspended magnetic beads (see Table 2) into a siliconized lowretention $1.5-\mathrm{mL}$ microcentrifuge tube on ice.

6. Remove the Dynabeads buffer from the magnetic beads by leaving the tube in its magnetic rack for 20-30 sec and then decanting or withdrawing the buffer with a pipette, being careful not to disturb the beads.

7. Wash the beads three times ( 5 min each) in Dynabeads blocking buffer by rotating the tubes on a rotator $(10 \mathrm{rpm})$ at room temperature. After each wash, remove the buffer as described in Step 6.

8. Add the appropriate amount of antibody (or Ig control) to the beads (see Table 2) and adjust the total volume to $400 \mu \mathrm{L}$ (to ensure mixing) with blocking buffer. Saturate the beads with antibodies by rotating the tubes on a rotator $(10 \mathrm{rpm})$ for $1 \mathrm{~h}$ at room temperature or overnight at $4^{\circ} \mathrm{C}$.

TABLE 2. Coupling affinity-purified antibodies to magnetic Dynabeads M-280 sheep anti-rabbit/mouse IgG

\begin{tabular}{llcc}
\hline Experiment & Beads $(\mu \mathrm{L})$ & Antibody $(\mu \mathrm{g})$ & $\begin{array}{c}\text { No. of cells expressing } \\
\text { protein of interest }\end{array}$ \\
\hline ChIP-qPCR & 30 & $0.5-0.75$ & $400,000-600,000$ \\
ChIP-Seq & $100-300$ & $3-10$ & $4,000,000-12,000,000$ \\
\hline
\end{tabular}

These rough guidelines were established for $X$. tropicalis embryos at the late gastrula stage. According to the manufacturer's technical bulletin, $20 \mu \mathrm{L}$ of Dynabeads M-280 sheep anti-rabbit or anti-mouse IgG are capable of binding $0.1-1 \mu \mathrm{g}$ of antibody. 
The antibody-saturated beads will keep from several days to weeks at $4{ }^{\circ} \mathrm{C}$ depending on the antibody, but it is best to use them in Step 28 immediately or within 1-2 d.

\section{Extracting Nuclei from Fixed Embryos}

The extraction of nuclei from fixed embryonic tissue works best with fixation times as outlined in Step 2 and no more than 50-80 X. tropicalis gastrula-stage embryos or 25-40 X. laevis gastrula-stage embryos per milliliter of extraction buffer (E1, E2, and E3). If more embryos are required for a ChIP experiment, it is best to use multiple 2-mL microcentrifuge tubes or 15- or 50-mL conical tubes. Because the yolk content decreases during development, it may be possible to increase the number of embryos per milliliter of extraction buffer after the gastrula stage. During Steps 9-15, keep all biological samples and solutions on ice.

9. Supplement the extraction buffers E1, E2, and E3 (Lee et al. 2006) as follows immediately before use.

i. Supplement all three buffers with $0.2 \mathrm{~mm}$ PMSF and protease inhibitor tablets ( 1 mini tablet per $10 \mathrm{~mL}$ or 1 ultra tablet per $50 \mathrm{~mL}$ ).

ii. Supplement buffer E1 with 1 mм DTT.

iii. If it is necessary to block phosphatase activity, to each of the buffers add $\mathrm{NaF}$ to a final concentration of $5 \mathrm{~mm}$ and $\mathrm{Na}_{3} \mathrm{VO}_{4}$ to $2 \mathrm{~mm}$.

10. Homogenize the fixed embryonic tissue with E1 by pipetting up and down. Centrifuge the homogenate at $1000 \mathrm{~g}$ for $2-5 \mathrm{~min}$ in a refrigerated $\left(4^{\circ} \mathrm{C}\right)$ centrifuge, and then aspirate the supernatant and any lipids attached to the wall.

11. Resuspend the pellet in E1, keep the suspension on ice for 5-10 min, and then centrifuge and aspirate as in Step 10.

12. Resuspend the pellet in E2, and then centrifuge and aspirate as in Step 10.

13. Repeat Step 12, but keep the suspension on ice for 5-10 min before centrifugation.

14. Resuspend pellet in E3, and then centrifuge and aspirate as in Step 10.

The anionic detergents deoxycholate and N-lauroylsarcosine in E3 facilitate solubilization of yolk platelets. This step thus facilitates the separation of yolk from a fairly pure population of cross-linked nuclei (Gentsch et al. 2013). On very efficient extraction of cross-linked nuclei, the nuclear pellet is hardly visible. However, it may appear brown because of some unsolubilized pigment particles. Note that without formaldehydemediated cross-linking, these anionic detergents would solubilize the chromatin and this purification step would not work.

15. Resuspend the pellet of cross-linked nuclei in a total volume of at least $500 \mu \mathrm{L}$ of E3 for sonication. If the nuclear suspension appears very viscous, dilute it with E3 to a total volume of 1-3 mL. If several samples were created, pool them at this stage (i.e., before sonication).

\section{Shearing Cross-Linked Chromatin}

Shearing of cross-linked chromatin can be achieved by sonication with a commercially available sonicator. Here we describe the parameters used with a Misonix Sonicator 3000 Ultrasonic Liquid Processor equipped with a tapered $1 / 16$ inch $(1.6 \mathrm{~mm})$ microtip. Other laboratories have successfully used different sonicators such as those from Branson or Covaris. When using these sonicators, follow the manufacturers' instructions and optimize the parameters empirically.

16. Score and clip a $15 \mathrm{~mL}$ polystyrene tube at the $7 \mathrm{~mL}$ mark, for use as a vessel for shearing chromatin.

17. Transfer the solution with cross-linked nuclei into this conical tube, and keep it chilled during sonication by attaching the tube to a plastic beaker filled with ice water via a short thermometer clamp. With a laboratory jack, move the beaker/tube vertically and horizontally so that the sonicator microtip is immersed in the sample to about two-thirds of the volume depth and properly centered without contacting the tube wall.

Off-center positioning of the microtip relative to the tube can cause frothing of the sample.

18. Sonicate the sample of cross-linked nuclei. Expose the sample to 10-14 cycles of 30-sec shock waves followed by 1-min pauses to avoid overheating the sample. Start sonication with a power 
G.E. Gentsch and J.C. Smith

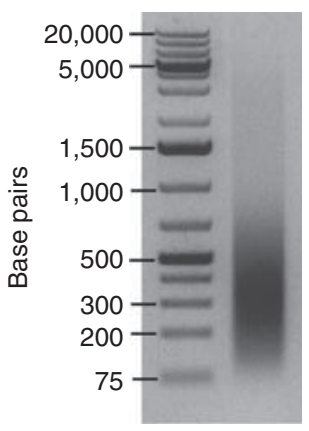

FIGURE 1. Sonication-mediated shearing of cross-linked chromatin from gastrula embryos. The image shows the results of gel electrophoresis of genomic DNA purified from crosslinked chromatin. The chromatin sample was sheared by 10 cycles of sonication (30-sec shock waves followed by $1-\min$ pauses) at $6-9 \mathrm{~W}$.

setting of $1.0 \mathrm{~W}$, and change the power setting (depending on volume and ionic strength of sample) to reach 6-12 W for efficient shearing. If the sample begins to froth, pause immediately, reposition the tube, and wait until the froth disappears before resuming sonication.

These settings produce an asymmetric DNA fragment distribution in the range of 100-500 bp, peaking at 200-300 bp (Fig. 1).

19. After sonication, transfer the chromatin solution into microcentrifuge tubes, and remove the debris by centrifuging at full speed $(>15,000 \mathrm{~g})$ for $10 \mathrm{~min}$ at $4^{\circ} \mathrm{C}$.

20. Transfer the clear supernatant containing solubilized and sheared chromatin to a clean, prechilled 1.5-mL microcentrifuge tube.

21. Collect a chromatin sample $(\sim 50 \mu \mathrm{L})$ corresponding to $\sim 400,000$ or more nuclei $(\sim 10$ gastrula embryos) to check the efficiency of chromatin shearing (see Steps 22-27). Use the remaining chromatin for immunoprecipitation (see Steps $28-38$ ). Keep it at $4^{\circ} \mathrm{C}$ if it will be used on the same or following day; alternatively, snap-freeze the sample in liquid nitrogen and store it at $-80^{\circ} \mathrm{C}$ for later use.

Storage at $4^{\circ} \mathrm{C}$ or at $-80^{\circ} \mathrm{C}$ does not affect the outcome.

\section{Checking the Efficiency of Chromatin Shearing}

Efficient shearing of chromatin is important, because the resultant fragment size distribution determines the positional resolution of binding events. This is particularly true for ChIP-qPCR, which does not include a fragment size-selection step before PCR amplification.

22. Add at least one volume of fresh SDS elution buffer to the chromatin sample (e.g., $50 \mu \mathrm{L}$ of SDS elution buffer to $50 \mu \mathrm{L}$ of solubilized chromatin).

23. Add $1 / 20$ volume of $5 \mathrm{M} \mathrm{NaCl}$ to the chromatin solution (e.g., $\sim 5 \mu \mathrm{L}$ of $5 \mathrm{M} \mathrm{NaCl}$ to $\sim 100 \mu \mathrm{L}$ of sample) to enhance the reversal of cross-links at $65^{\circ} \mathrm{C}$.

24. Incubate the chromatin solution for $6-15 \mathrm{~h}$ (overnight) in an oven set to $65^{\circ} \mathrm{C}$.

25. Add proteinase $\mathrm{K}$ to the chromatin solution to a final concentration of $200 \mu \mathrm{g} / \mathrm{mL}$ (e.g., $\sim 1 \mu \mathrm{L}$ of $20 \mu \mathrm{g} / \mu \mathrm{L}$ proteinase $\mathrm{K}$ to $\sim 100 \mu \mathrm{L}$ of sample). Incubate for $2 \mathrm{~h}$ at $55^{\circ} \mathrm{C}$.

26. Purify the DNA fragments using the QIAquick PCR Purification Kit according to the manufacturer's instructions. Elute the DNA with $30 \mu \mathrm{L}$ of Buffer EB (provided with the kit).

27. Add $\sim 4 \mu \mathrm{g}$ of RNase A to remove any residual RNA. Incubate for $5 \mathrm{~min}$ at $37^{\circ} \mathrm{C}$ before running the entire sample on a $1.4 \%$ agarose gel by electrophoresis.

An asymmetric DNA fragment distribution should be visible, mainly within the range of 100-500 bp, peaking at $\sim 200-300 \mathrm{bp}$ (Fig. 1). If shearing of cross-linked chromatin was successful, continue with Step 28; otherwise, see Troubleshooting.

\section{Immunoprecipitation of Sheared Chromatin}

Use siliconized low-retention $1.5 \mathrm{~mL}$ microcentrifuge tubes to collect chromatin at any given step. Use 1.0-1.4 mL of indicated buffer to wash beads at any washing step. 
28. Wash the beads coupled to antibody (or Ig control) from Step 8.

i. Wash the beads twice ( 5 min each) in Dynabead blocking buffer by rotating the tubes on a rotator $(10 \mathrm{rpm})$ at $4^{\circ} \mathrm{C}$. After each wash, remove the Dynabeads buffer from the magnetic beads by leaving the tubes in their magnetic rack for 20-30 sec and then decanting or withdrawing the buffer with a pipette, being careful not to disturb the beads.

ii. Wash the beads once (for $5 \mathrm{~min}$ ) in buffer E2 containing 1\% Triton X-100 by rotating the tubes on a rotator $(10 \mathrm{rpm})$ at $4^{\circ} \mathrm{C}$. Remove the buffer as in Step 28.i.

29. From the sheared chromatin preparation (Step 21), collect a sample that is equivalent to $3 \%-10 \%$ of the ChIP input (e.g., if the $275-\mu \mathrm{L}$ sample in Step 31 will contain $\sim 250 \mu \mathrm{L}$ of sheared chromatin, take $\sim 25 \mu \mathrm{L}$ here). Transfer the sample to a new tube and store at $4^{\circ} \mathrm{C}$.

This sample will be processed further once the ChIP samples are ready for the reversal of cross-links (Step 39), and used as input to create locus-specific qPCR standard curves or ChIP-Seq control libraries.

30. To the sheared chromatin from Step 21, add ice-cold 10\% Triton X-100 to a final concentration of $1 \%$ (e.g., add $55 \mu \mathrm{L}$ of $10 \%$ Triton $\mathrm{X}-100$ to a $500-\mu \mathrm{L}$ volume of sheared chromatin).

31. Add the sheared chromatin from Step 30 to the beads from Step 28. If using an Ig control (for a ChIP-qPCR experiment), add half of the sheared chromatin from Step 30 to the beads coupled to antibody and the other half to the beads coupled to the Ig control (i.e., add $275 \mu \mathrm{L}$ of sample from Step 30 to each tube). Incubate on a rotator $(10 \mathrm{rpm})$ overnight at $4^{\circ} \mathrm{C}$.

32. The following day, wash the beads extensively.

i. Remove the unbound chromatin from the magnetic beads by leaving the tubes in their magnetic rack for 20-30 sec and then decanting or withdrawing the solution with a pipette, being careful not to disturb the beads.

ii. Wash the beads four times (for ChIP-qPCR) or ten times (for ChIP-Seq) ( 5 min each) with prechilled RIPA buffer by rotating the tubes on a rotator $(10 \mathrm{rpm})$ at $4^{\circ} \mathrm{C}$. Remove the buffer as in Step 32.i.

iii. Wash the beads once (for $5 \mathrm{~min}$ ) in prechilled TEN buffer by rotating the tubes on a rotator $(10 \mathrm{rpm})$ at $4^{\circ} \mathrm{C}$. Remove the buffer as in Step 32.i.

Different washing conditions such as higher salt concentrations (giving higher stringency) can be used to improve the signal-to-noise ratio. The following washing buffers have also frequently been used in the indicated order: low-salt solution buffer, high-salt solution buffer, and LiCl solution buffer.

For ChIP-Seq, continue with Step 33; for ChIP-qPCR, skip to Step 36. Steps 33 to 35 help to reduce the number of background fragments in a ChIP-Seq experiment. These steps are not required when performing ChIP-qPCR.

33. Resuspend the beads in $50 \mu \mathrm{L}$ of prechilled TEN buffer, and transfer the bead suspension to a new tube. If several tubes of the same ChIP experiment are in use, pool the samples at this stage.

34. Use the magnetic rack to assemble beads at the bottom of the tube.

35. Centrifuge the tube at $1000 \mathrm{~g}$ for $1 \mathrm{~min}$ at $4^{\circ} \mathrm{C}$, and remove the supernatant while keeping the bottom of the tube adjacent to the magnetic rack.

The combination of Steps 34 and 35 ensures that the beads are collected at the bottom of the tube. Centrifugation alone may not be sufficient; some heads can stick to the tube wall in the absence of any detergent.

36. Add fresh SDS elution buffer to beads. Use $100 \mu \mathrm{L}$ for ChIP-qPCR or $200 \mu \mathrm{L}$ for ChIP-Seq.

The recovery of immunoprecipitated DNA may be improved by eluting twice with SDS elution buffer, using either $50 \mu \mathrm{L}$ (for ChIP-qPCR) or $100 \mu \mathrm{L}$ (for ChIP-Seq) each time.

37. Shake the beads for $15 \mathrm{~min}$ in a thermomixer set to $1000 \mathrm{rpm}$ and $65^{\circ} \mathrm{C}$.

Alternatively, shake the beads every 5 min on a vortex. During the interim, incubate at $65^{\circ} \mathrm{C}$. 
G.E. Gentsch and J.C. Smith

38. Centrifuge the tube at full speed $(>15,000 \mathrm{~g})$ for $30 \mathrm{sec}$ at room temperature. Transfer the supernatant to a new tube.

If the DNA is to be eluted twice, repeat Steps 36-38, and then transfer the supernatant from the second elution to the tube containing the supernatant from the first elution.

\section{Recovery and Extraction of the DNA}

39. Add at least one volume of fresh SDS elution buffer to the input sample collected at Step 29, typically to a final volume of $100 \mu \mathrm{L}$ (for ChIP-qPCR) or $200 \mu \mathrm{L}$ (for ChIP-Seq).

40. Add $1 / 20$ volume of $5 \mathrm{M} \mathrm{NaCl}$ to all ChIP and input samples (e.g., add $\sim 5 \mu \mathrm{L}$ of $5 \mathrm{M} \mathrm{NaCl}$ to $\sim 100$ $\mu \mathrm{L}$ of sample).

41. Incubate the chromatin solution(s) for $6-15 \mathrm{~h}$ (overnight) in an oven set to $65^{\circ} \mathrm{C}$.

42. Dilute the samples with one volume of TE buffer (e.g., add $\sim 100 \mu \mathrm{L}$ of TE buffer to $\sim 100 \mu \mathrm{L}$ of sample from Step 41).

43. Add RNase A to a final concentration of $200 \mu \mathrm{g} / \mathrm{mL}$ (e.g., add $\sim 2 \mu \mathrm{L}$ of $20 \mu \mathrm{g} / \mu \mathrm{L}$ RNase A to $\sim 200 \mu \mathrm{L}$ of sample from Step 42$)$. Incubate for $1 \mathrm{~h}$ at $37^{\circ} \mathrm{C}$.

44. Add proteinase $\mathrm{K}$ to a final concentration of $200 \mu \mathrm{g} / \mathrm{mL}$ (e.g., add $\sim 2 \mu \mathrm{L}$ of $20 \mu \mathrm{g} / \mu \mathrm{L}$ proteinase $\mathrm{K}$ to $\sim 200 \mu \mathrm{L}$ of sample from Step 43 ). Incubate for $2-4 \mathrm{~h}$ at $55^{\circ} \mathrm{C}$.

45. Extract the DNA fragments using the QIAquick PCR Purification Kit or phenol:chloroform: isoamyl alcohol purification followed by ethanol precipitation.

To extract DNA using the kit:

i. Follow the manufacturer's instructions for the QIAquick PCR Purification Kit.

ii. Add $3 \mathrm{M}$ sodium acetate ( $\mathrm{pH}$ 5.2) as outlined in the manufacturer's instructions (Step 2).

iii. Elute the DNA with $30-80 \mu \mathrm{L}$ of Buffer EB prewarmed to $50^{\circ} \mathrm{C}$.

To extract the DNA using phenol:chloroform:isoamyl alcohol purification and ethanol precipitation:

i. Prespin 1.5-mL Phase-Lock Gel Heavy tubes at 12,000 $\mathrm{g}$ for $30 \mathrm{sec}$ at room temperature.

ii. Transfer the DNA samples from Step 44 to the prespun tubes, add one volume of phenol: chloroform:isoamyl alcohol (25:24:1; pH 7.9), and mix the samples by inverting the tubes four to six times.

iii. Centrifuge the tubes at full speed $(>15,000 \mathrm{~g})$ for $5 \mathrm{~min}$ at room temperature.

iv. Transfer the upper (aqueous) phase to a fresh tube. Add 1/25 volume of $5 \mathrm{M} \mathrm{NaCl}$, two volumes of $100 \%$ ethanol, and $15 \mu \mathrm{g}$ of GlycoBlue. Mix the sample by inverting the tube four to six times.

v. Incubate the samples overnight at $-20^{\circ} \mathrm{C}$.

vi. Centrifuge the samples at full speed $(>15,000 g)$ for $1 \mathrm{~h}$ at $4^{\circ} \mathrm{C}$, and then discard the supernatant without disturbing the blue DNA pellet.

vii. Wash the pellet with $500 \mu \mathrm{L}$ of $80 \%$ ethanol.

viii. Centrifuge the samples at full speed $(>15,000 \mathrm{~g})$ for $3 \mathrm{~min}$ at $4^{\circ} \mathrm{C}$, and then discard the supernatant without disturbing the blue DNA pellet.

ix. Air-dry the DNA pellet for 5-10 min at room temperature.

x. Add $32 \mu \mathrm{L}$ of molecular-grade water to the dry DNA pellet, and leave samples on ice for at least $2 \mathrm{~h}$ to ensure that the DNA is completely dissolved.

We prefer to use the QIAquick PCR Purification Kit for ChIP-qPCR because of its high reproducibility and time efficiency, and phenol:chloroform:isoamyl alcohol purification followed by ethanol precipitation for ChIP-Seq because of its superior DNA purification and recovery yield. After extraction, the 
DNA is ready for qPCR or for making ChIP-Seq libraries (see Discussion). ChIP-isolated DNA samples can be stored at $-20^{\circ} \mathrm{C}$.

46. If the goal is to create ChIP-Seq libraries, quantify $1 \mu \mathrm{L}$ of the immunoprecipitated DNA and the diluted input DNA using the Qubit Fluorometer (or an equivalent spectroscopic instrument).

A total of 5-10 ng of DNA is currently required for creating a robust single-end ChIP-Seq library using the Illumina protocol (see Discussion).

\section{TROUBLESHOOTING}

Problem (Step 27): The DNA fragments are longer or shorter than expected (i.e., average $>500 \mathrm{bp}$ ).

Solution: Try shearing the chromatin again, beginning at Step 16. However, poor shearing efficiency often relates to inefficient nuclear extraction or prolonged cross-linking rather than inefficient sonication (see Discussion). Stronger chromatin shearing can be achieved by moderately increasing either or both the sonication power and/or the concentration of anionic detergents such as $\mathrm{N}$ lauroylsarcosine, deoxycholate, or SDS. Be aware that stronger sionication may cause the sample to froth and epitopes to be stripped off the chromatin. In addition, higher concentration of anionic detergents can render the ChIP ineffective as antibodies uncouple from the beads and their epitope affinity is reduced. This denaturation may be alleviated by diluting the sheared chromatin samples before adding the antibody-coupled beads.

Problem: Immunoprecipitation is poor (no or low-level enrichment) as judged by ChIP-qPCR with positive and negative controls (see Discussion).

Solution: We encountered that some ChIP-grade antibodies are not compatible with the use of $\mathrm{N}$ lauroylsarcosine. Modify E3 recipe by replacing $N$-lauroylsarcosine with $0.1 \%$ SDS. Alternatively, try another antibody as not all antibodies are suitable for ChIP.

\section{DISCUSSION}

This protocol was devised to prepare ChIP-isolated DNA from Xenopus embryos for sequencing (ChIP-Seq) or for qPCR. It includes modifications from standard protocols (Jallow et al. 2004; Buchholz et al. 2005; Lee et al. 2006; Acevedo et al. 2007) that allow for the high yolk content of Xenopus embryos. It provides an alternative to other protocols (Blythe et al. 2009; Akkers et al. 2012) and can be easily scaled up to process thousands of embryos, which are sometimes required to create robust ChIP-Seq libraries. It has been successfully tested with embryos from both X. tropicalis and X. laevis, as well as from the zebrafish Danio rerio (Gentsch et al. 2013; Miyamoto et al. 2013).

\section{Comments on the ChIP Procedure}

The number of embryos required for a particular ChIP experiment depends on the number of cells expressing the nuclear protein of interest, average DNA occupancy levels within nuclei, DNA crosslinking efficiencies, and the ChIP-grade quality of the antibody used. Normally, fewer embryos are required for ChIP when epitope-tagged fusion proteins are introduced. In this case, embryos not expressing this construct may be used as a negative control. This method can be legitimate and informative when ChIP-grade antibodies are not available or if there are not enough cells expressing the protein of interest (Mazzoni et al. 2011). However, bear in mind that DNA occupancy levels will reflect exogenous (nonnative) expression.

Based on shearing efficiency experiments, nuclei of later-staged embryos seem more susceptible to formaldehyde fixation than those of gastrula or pregastrula embryos, perhaps because of the gradual 
depletion of yolk during early embryogenesis. Fixation time may also be extended up to $1 \mathrm{~h}$ for proteins indirectly associated with DNA. However, under conditions of prolonged fixation, chromatin shearing becomes more difficult and requires more rounds of sonication than recommended in this protocol (Step 18).

The embryos are washed in amphibian medium immediately after fixation (Step 3); these washes facilitate efficient shearing of the chromatin and do not contain glycine. We have found that immediate quenching with glycine makes the extraction of fixed nuclei very difficult. Glycine is generally thought not to have cross-linking capacity. However, because of its monovalent nature, the formaldehyde-glycine (Schiff-base) adduct can further react with amino-terminal amino groups or arginine residues (Metz et al. 2004). It is not clear, however, whether this, or the fact that Xenopus cells are relatively rich in yolk, is the reason for the problems that were encountered.

\section{Analyzing ChIP-Isolated DNA by qPCR}

In ChIP-qPCR, DNA enrichment is quantified relative to locus-specific standard curves or by the $2^{-\Delta \Delta C(T)}$ method using real-time PCR (Livak and Schmittgen 2001; Blythe et al. 2009). DNA occupancy levels can be visualized as a percentage of input DNA (see Fig. 2A) or as a ratio of ChIP versus Ig control. If known, include a negative (not bound) control locus as well as a positive (bound) control locus. A successful ChIP experiment yields significant DNA enrichment for protein binding at positive control loci and no enrichment at negative control loci. The antibody control (nonspecific immunoglobulins) should not give any enrichment at positive or negative control loci (see Troubleshooting).

\section{Creating and Analyzing ChIP-Seq Libraries}

We use the ChIP-Seq Sample Prep Kit (Illumina IP-102-1001) to create ChIP-Seq libraries. The same amounts of input and of ChIP DNA should be used to create separate libraries according to the manufacturer's instructions. We recommend the use of DNA Clean \& Concentrator5 Kit (Zymo Research) to purify DNA, E-gel (Invitrogen) to size-select DNA fragments, and solid-phase reverse immobilization beads to remove adaptors and primer dimers from the final PCR reaction. Libraries should be quantified by fluorometry and quality-controlled on microfluidics-based platforms. A good-quality library suitable for deep sequencing shows a single bell-shaped distribution of DNA fragments of the selected size (Fig. 2B) and does not contain any primer/adaptor dimers (peak $\sim 70-100 \mathrm{bp}$ ). Mapped reads of the input library will be subtracted from the genome-wide ChIP profile to account for any shearing bias and other experimental artefacts.

In the remaining discussion, we briefly outline our approach for analyzing ChIP-Seq data derived from $X$. tropicalis embryos. However, there are several other tools that offer equivalent or perhaps even better postsequencing analyses. Some tools may not work well because of the fragmented state of the current X. tropicalis genome draft (JGI4.1 or JGI7.1).

On sequencing of the library on a deep sequencing platform, the read quality can quickly be verified with FastQC (developed by S. Andrews at the Babraham Institute, UK). Only reads with unambiguous matches are subsequently mapped to the Xenopus genome using a read aligner such as Bowtie (Langmead et al. 2009; Langmead and Salzberg 2012). To find regions of DNA fragment enrichment, or so called peaks, several programs are available such as MACS (Zhang et al. 2008; Feng et al. 2012), PeakSeq (Rozowsky et al. 2009) or SPP (van Rooijen et al. 2012). We prefer MACS, which accepts the compressed (binary) file of mapped reads (BAM-file) and delivers genomic coordinates, $p$-values and rate of false discoveries for each peak in the format of an excel spreadsheet or bed file. It also supports the comparison of ChIP versus input (control) DNA (two-sample analysis based on Poisson distribution of reads), which is important because the control distribution of reads features nonrandom enrichment. In addition, it produces bedGraph files, which, once converted into the bigWig format, can be displayed as custom tracks on the UCSC Genome 
A

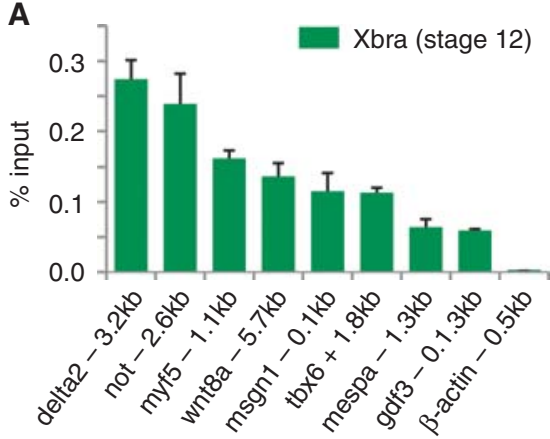

B

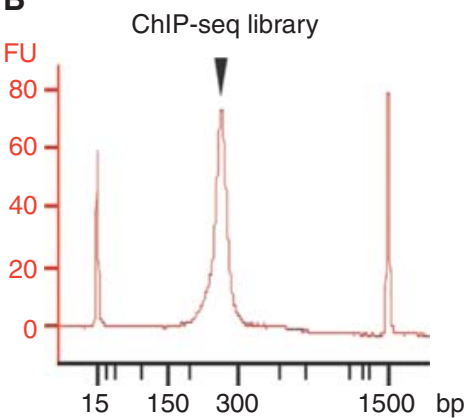

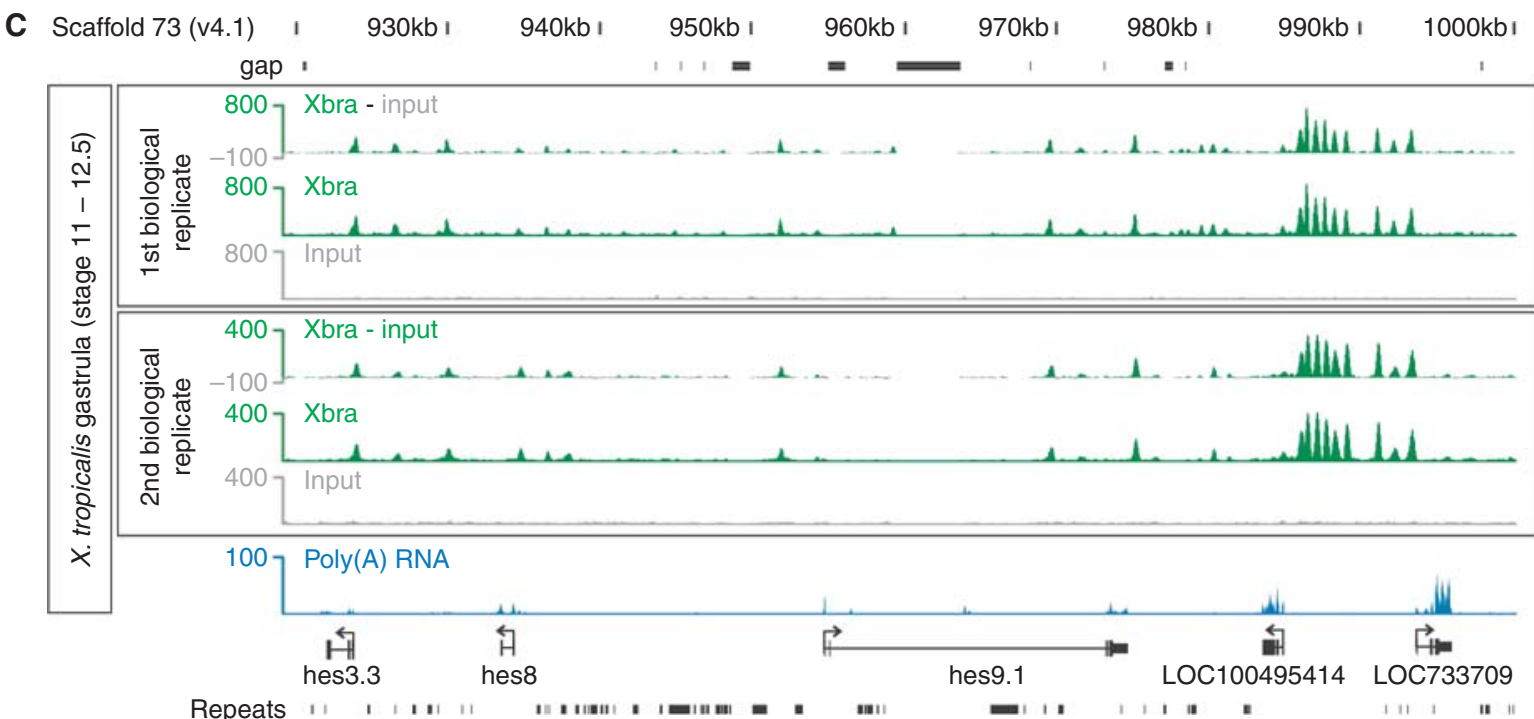

FIGURE 2. Mapping physical chromatin associations across the $X$. tropicalis genome by ChIP-qPCR and ChIP-Seq. (A) DNA occupancy levels of Brachyury (Xbra) at various genomic loci as determined at the late gastrula stage by ChIPqPCR. DNA occupancy levels are indicated as percentage (\%) of input. The genomic locus upstream of the housekeeping gene $\beta$-actin is used as a negative control (not bound by Xbra). Error bar, standard deviation from mean (biological duplicates). (B) Microfluidics-mediated quality control of a ChIP-Seq library with an average fragment length of $\sim 270 \mathrm{bp}$, visualized with lower (15 bp) and upper (1500 bp) ladder markers. FU, fluorescence units. (C) Excerpt of a genome-wide Brachyury (Xbra) binding profile as determined at gastrula stage by ChIP-Seq showing the hairy and enhancer of split (hes) gene cluster (hes3.3, hes8, hes9.1, LOC100495414, and LOC733709). Profiles are pile-ups of extended reads from ChIP and input libraries (biological replicates) mapped to genome draft 4.1. The input profile was subtracted from the ChIP profile for normalization purposes. Data sets for $A$ and $C$ are from Gentsch et al. (2013), and the poly(A) RNA track in C is from Akkers et al. (2009).

Browser (Fig. 2C) or the Integrative Genomics Viewer (Robinson et al. 2011). The nearest genes to peaks can be found by ranking distances between peak summits and transcription start sites using query language MySQL or by running a Perl script (annotatePeaks.pl) from HOMER (Heinz et al. 2010). Genomic features such as gene coordinates, name and description can be downloaded from the Ensembl browser via BioMart (http://www.ensembl.org/biomart/) or from the UCSC Genome Browser via the Table Browser as a tab-separated plain text file. The extraction of statistically enriched DNA motifs over background from peak regions can be achieved by online platforms such as cisFinder (Sharov and Ko 2009) or MEME (Storey et al. 1995). The HOMER script collection also contains useful command-line tools to create read (tag) density matrices aligned to any chosen genomic element such as transcription start sites or transcription factor binding sites. These matrices, possibly including several ChIP-Seq experiments, can be clustered and visualized with an open-source software combination of Cluster3 (Eisen et al. 1998; de Hoon et al. 2004) and JavaTreeview (http:// 
G.E. Gentsch and J.C. Smith

jtreeview.sourceforge.net/) or functional language R/Bioconductor. The latter provides a wealth of readily developed tools to combine ChIP-Seq with other types of data sets such as those supporting differential gene expression analyses.

\section{RECIPES}

\section{E1 Buffer for ChIP}

Reagent Amount (for $50 \mathrm{~mL}$ ) Final concentration

HEPES-KOH (1 M, pH 7.5)

$\mathrm{NaCl}(5 \mathrm{M})$

EDTA (0.5 M, pH 8.0)

Glycerol (100\%)

Igepal CA-630 (10\%)

Triton X-100 (10\%)

Double-distilled water

$2.5 \mathrm{~mL}$

$1.4 \mathrm{~mL}$

$100 \mu \mathrm{L}$

$5 \mathrm{~mL}$

$2.5 \mathrm{~mL}$

$1.25 \mathrm{~mL}$

$37.25 \mathrm{~mL}$
$50 \mathrm{~mm}$

$140 \mathrm{~mm}$

$1 \mathrm{~mm}$

$10 \%$

$0.5 \%$

$0.25 \%$

Store for up to several months at $4^{\circ} \mathrm{C}$.

\section{E2 Buffer for ChIP}

\begin{tabular}{lcc} 
Reagent & Amount $($ for $50 \mathrm{~mL})$ & Final concentration \\
\hline Tris-HCl $(1 \mathrm{M}, \mathrm{pH} 8.0)$ & $500 \mu \mathrm{L}$ & $10 \mathrm{~mm}$ \\
$\mathrm{NaCl}(5 \mathrm{M})$ & $2 \mathrm{~mL}$ & $200 \mathrm{~mm}$ \\
EDTA $(0.5 \mathrm{M}, \mathrm{pH} 8.0)$ & $100 \mu \mathrm{L}$ & $1 \mathrm{~mm}$ \\
EGTA $(0.5 \mathrm{M}, \mathrm{pH} 8.0)$ & $50 \mu \mathrm{L}$ & $0.5 \mathrm{~mm}$ \\
Double-distilled water & $47.35 \mathrm{~mL}$ & -
\end{tabular}

Store for up to several months at $4^{\circ} \mathrm{C}$.

\section{E3 Buffer for ChIP}

Reagent

Tris- $\mathrm{HCl}(1 \mathrm{M}, \mathrm{pH} 8.0)$

$\mathrm{NaCl}(5 \mathrm{M})$

EDTA (0.5 M, pH 8.0)

EGTA (0.5 M, pH 8.0)

Sodium deoxycholate $(10 \%[\mathrm{w} / \mathrm{v}])$

Sodium $N$-lauroylsarcosine $(10 \%[\mathrm{w} / \mathrm{v}])$

Double-distilled water

Store for up to several months at $4^{\circ} \mathrm{C}$.
Amount (for $50 \mathrm{~mL}$ ) Final concentration

$\begin{array}{rr}500 \mu \mathrm{L} & 10 \mathrm{mM} \\ 2 \mathrm{~mL} & 200 \mathrm{mM} \\ 100 \mu \mathrm{L} & 1 \mathrm{mM} \\ 50 \mu \mathrm{L} & 0.5 \mathrm{mM} \\ 500 \mu \mathrm{L} & 0.1 \%(\mathrm{w} / \mathrm{v}) \\ 2.5 \mathrm{~mL} & 0.5 \%(\mathrm{w} / \mathrm{v})\end{array}$

$44.35 \mathrm{~mL}$

\section{HEG Solution}

Reagent Amount for $10 \mathrm{~mL}$

Final concentration

HEPES-KOH (1 M, pH 7.5)

EDTA $(0.5 \mathrm{M}, \mathrm{pH} 8.0)$

Glycerol (100\%)

Double-distilled water

$\begin{array}{rr}500 \mu \mathrm{L} & 50 \mathrm{mM} \\ 20 \mu \mathrm{L} & 1 \mathrm{mM} \\ 2 \mathrm{~mL} & 20 \% \\ 7.5 \mathrm{~mL} & -\end{array}$


Chromatin Immunoprecipitation on Xenopus Embryos

High-Salt Solution Buffer

Reagent

Amount for $50 \mathrm{~mL}$

Final concentration

Tris- $\mathrm{HCl}(1 \mathrm{M}, \mathrm{pH} 8.0)$

EDTA (0.5 M, pH 8.0)

$500 \mu \mathrm{L}$

$10 \mathrm{~mm}$

$100 \mu \mathrm{L}$

$1 \mathrm{~mm}$

$\mathrm{NaCl}(5 \mathrm{M})$

Triton X-100 (10\%)

$5 \mathrm{~mL}$

$500 \mathrm{~mm}$

Double-distilled water

$5 \mathrm{~mL}$

$39.4 \mathrm{~mL}$

$1 \%$

LiCl Solution Buffer

Reagent

Tris-HCl (1 M, pH 8.0)

EDTA (0.5 M, pH 8.0)

$\mathrm{LiCl}(7.5 \mathrm{M})$

Igepal CA-630 (10\%)

Sodium deoxycholate

$(10 \%[\mathrm{w} / \mathrm{v}])$

Double-distilled water

Low-Salt Solution Buffer

Reagent

Amount (for $50 \mathrm{~mL}$ )

\section{$500 \mu \mathrm{L}$}

$100 \mu \mathrm{L}$

$1.5 \mathrm{~mL}$

$5 \mathrm{~mL}$

$42.9 \mathrm{~mL}$

EDTA (0.5 M, pH 8.0)

$\mathrm{NaCl}(5 \mathrm{M})$

Triton X-100 (10\%)

Double-distilled water

$37.7 \mathrm{~mL}$

Final concentration

$\begin{array}{rr}500 \mu \mathrm{L} & 10 \mathrm{mM} \\ 100 \mu \mathrm{L} & 1 \mathrm{mM} \\ 1.67 \mathrm{~mL} & 250 \mathrm{mM} \\ 5 \mathrm{~mL} & 1 \% \\ 5 \mathrm{~mL} & 1 \%\end{array}$

Marc's Modified Ringer's for Xenopus ChIP

Reagent

Concentration $(10 \times)$

\begin{tabular}{lr}
\hline $\mathrm{NaCl}$ & $1 \mathrm{M}$ \\
$\mathrm{KCl}$ & $20 \mathrm{~mm}$ \\
$\mathrm{CaCl}_{2}$ & $20 \mathrm{~mm}$ \\
$\mathrm{MgSO}_{4}$ & $10 \mathrm{~mm}$ \\
$\mathrm{HEPES}(\mathrm{pH} \mathrm{7.5)}$ & $50 \mathrm{~mm}$
\end{tabular}

Adjust to $\mathrm{pH} 7.5$ and sterilize by autoclaving. Use the solution at $0.01 \times$.

Normal Amphibian Medium

Reagent

Concentration $(10 \times)$

$\begin{array}{lr}\mathrm{NaCl} & 1.1 \mathrm{M} \\ \mathrm{KCl} & 20 \mathrm{~mm} \\ \mathrm{Ca}\left(\mathrm{NO}_{3}\right)_{2} & 10 \mathrm{~mm} \\ \mathrm{MgSO}_{4} & 10 \mathrm{~mm} \\ \mathrm{EDTA} & 1 \mathrm{~mm}\end{array}$

Use this solution at $0.1 \times$, supplemented with $2 \mathrm{~mm}$ sodium phosphate $(\mathrm{pH} 7.5)$ from a

$50 \times$ stock ( 0.1 m sodium phosphate buffer). 
G.E. Gentsch and J.C. Smith

PBS (A)

Reagent

Amount to add for $1 \mathrm{~L}$

Final concentration

$\begin{array}{lrr}\mathrm{NaCl} & 8.0 \mathrm{~g} & 137.0 \mathrm{mM} \\ \mathrm{KCl} & 0.2 \mathrm{~g} & 2.7 \mathrm{mM} \\ \mathrm{KH}_{2} \mathrm{PO}_{4} & 0.2 \mathrm{~g} & 1.5 \mathrm{mM} \\ \mathrm{NaH}_{2} \mathrm{PO}_{4} & 1.14 \mathrm{~g} & 8.0 \mathrm{mM}\end{array}$

Adjust $\mathrm{pH}$ to 7.2 with $\mathrm{HCl}(\sim 4-6$ droplets of $6 \mathrm{M} \mathrm{HCl})$.

RIPA Buffer for Xenopus ChIP

Reagent Amount (for $50 \mathrm{~mL}$ ) Final concentration

$\begin{array}{lrr}\text { HEPES-KOH }(1 \mathrm{M}, \mathrm{pH} 7.5) & 2.5 \mathrm{~mL} & 50 \mathrm{~mm} \\ \text { LiCl }(7.5 \mathrm{M}) & 3.33 \mathrm{~mL} & 500 \mathrm{~mm} \\ \text { EDTA }(0.5 \mathrm{M}, \mathrm{pH} 8.0) & 100 \mu \mathrm{L} & 1 \mathrm{~mm} \\ \text { Igepal CA-630 }(10 \%) & 5 \mathrm{~mL} & 1 \% \\ \text { Sodium deoxycholate } & 3.5 \mathrm{~mL} & 0.7 \% \\ \quad(10 \% \text { [w/v] }) & & - \\ \text { Double-distilled water } & 35.6 \mathrm{~mL} & \end{array}$

SDS Elution Buffer

\begin{tabular}{lrr}
\hline Tris- $\mathrm{HCl}(1 \mathrm{M}, \mathrm{pH} 8.0)$ & $50 \mu \mathrm{L}$ & $50 \mathrm{~mm}$ \\
EDTA $(0.5 \mathrm{M}, \mathrm{pH} 8.0)$ & $2 \mu \mathrm{L}$ & $1 \mathrm{~mm}$ \\
SDS $(10 \%)$ & $100 \mu \mathrm{L}$ & $1 \%$ \\
Double-distilled water & $848 \mu \mathrm{L}$ & -
\end{tabular}

TEN Buffer for ChIP

Reagent Amount (for $50 \mathrm{~mL}$ ) Final concentration

Tris-HCl (1 M, pH 8.0)

EDTA (0.5 m, pH 8.0)

$500 \mu \mathrm{L}$

$10 \mathrm{~mm}$

$\mathrm{NaCl}(5 \mathrm{M})$

$100 \mu \mathrm{L}$

$1 \mathrm{~mm}$

Double-distilled water

$1.5 \mathrm{~mL}$

$150 \mathrm{~mm}$

$47.9 \mathrm{~mL}$

\section{ACKNOWLEDGMENTS}

We thank C. Brenner for implementing the $X$. tropicalis genome into HOMER and the Smith and Gilchrist labs for discussions and advice. All Xenopus studies complied fully with the UK Animals (Scientific Procedures) Act 1986 as implemented by the MRC National Institute for Medical Research. This work was supported by the Wellcome Trust and the Medical Research Council (program number U117597140). The authors declare no conflict of interest or competing financial interest.

\section{REFERENCES}

Acevedo LG, Iniguez AL, Holster HL, Zhang X, Green R, Farnham PJ. 2007. Genome-scale ChIP-chip analysis using 10,000 human cells. BioTechniques 43: 791-797.

Akkers RC, van Heeringen SJ, Jacobi UG, Janssen-Megens EM, Françoijs K-J, Stunnenberg HG, Veenstra GJC. 2009. A hierarchy of H3K4me3 and $\mathrm{H} 3 \mathrm{~K} 27 \mathrm{me} 3$ acquisition in spatial gene regulation in Xenopus embryos. Dev Cell 17: 425-434.
Akkers RC, Jacobi UG, Veenstra GJ. 2012. Chromatin immunoprecipitation analysis of Xenopus embryos. Methods Mol Biol 917: 279-292.

Blythe SA, Reid CD, Kessler DS, Klein PS. 2009. Chromatin immunoprecipitation in early Xenopus laevis embryos. Dev Dyn 238: 1422 1432.

Buchholz DR, Paul BD, Shi Y-B. 2005. Gene-specific changes in promoter occupancy by thyroid hormone receptor during frog metamorphosis. 
Implications for developmental gene regulation. J Biol Chem 280: $41222-41228$.

Dale L, Slack JM. 1987. Fate map for the 32-cell stage of Xenopus laevis. Development 99: 527-551.

de Hoon MJ, Imoto S, Nolan J, Miyano S. 2004. Open source clustering software. Bioinformatics 20: 1453-1454.

Eisen MB, Spellman PT, Brown PO, Botstein D. 1998. Cluster analysis and display of genome-wide expression patterns. Proc Natl Acad Sci 95: 14863-14868.

Feng J, Liu T, Qin B, Zhang Y, Liu XS. 2012. Identifying ChIP-seq enrichment using MACS. Nat Protoc 7: 1728-1740.

Gentsch GE, Owens ND, Martin SR, Piccinelli P, Faial T, Trotter MW, Gilchrist MJ, Smith JC. 2013. In vivo T-box transcription factor profiling reveals joint regulation of embryonic neuromesodermal bipotency. Cell Rep 4: 1185-1196.

Heinz S, Benner C, Spann N, Bertolino E, Lin YC, Laslo P, Cheng JX, Murre C, Singh H, Glass CK. 2010. Simple combinations of lineage-determining transcription factors prime cis-regulatory elements required for macrophage and B cell identities. Mol Cell 38: 576-589.

Jallow Z, Jacobi UG, Weeks DL, Dawid IB, Veenstra GJ. 2004. Specialized and redundant roles of TBP and a vertebrate-specific TBP paralog in embryonic gene regulation in Xenopus. Proc Natl Acad Sci 101: 1352513530.

Langmead B, Salzberg SL. 2012. Fast gapped-read alignment with Bowtie 2. Nat Methods 9: 357-359.

Langmead B, Trapnell C, Pop M, Salzberg SL. 2009. Ultrafast and memoryefficient alignment of short DNA sequences to the human genome. Genome Biol 10: R25.

Lee TI, Johnstone SE, Young RA. 2006. Chromatin immunoprecipitation and microarray-based analysis of protein location. Nature Protocols 1: 729-748.

Livak KJ, Schmittgen TD. 2001. Analysis of relative gene expression data using real-time quantitative PCR and the 2(-Delta Delta C(T)) method. Methods 25: 402-408.

Mazzoni EO, Mahony S, Iacovino M, Morrison CA, Mountoufaris G, Closser M, Whyte WA, Young RA, Kyba M, Gifford DK, et al. 2011.
Embryonic stem cell-based mapping of developmental transcriptional programs. Nat Methods 8: 1056-1058.

Metz B, Kersten GF, Hoogerhout P, Brugghe HF, Timmermans HA, de Jong A, Meiring $\mathrm{H}$, ten Hove J, Hennink WE, Crommelin DJ, et al. 2004. Identification of formaldehyde-induced modifications in proteins: Reactions with model peptides. J Biol Chem 279: 62356243.

Miyamoto K, Teperek M, Yusa K, Allen GE, Bradshaw CR, Gurdon JB. 2013. Nuclear Wave1 is required for reprogramming transcription in oocytes and for normal development. Science 341: 1002-1005.

Nieuwkoop PD, Faber J. 1994. Normal table of Xenopus laevis (Daudin): A systematical and chronological survey of the development from the fertilized egg till the end of metamorphosis. Garland, New York.

Robinson JT, Thorvaldsdottir H, Winckler W, Guttman M, Lander ES, Getz G, Mesirov JP. 2011. Integrative genomics viewer. Nat Biotechnol 29: $24-26$.

Rozowsky J, Euskirchen G, Auerbach RK, Zhang ZD, Gibson T, Bjornson R, Carriero N, Snyder M, Gerstein MB. 2009. PeakSeq enables systematic scoring of ChIP-seq experiments relative to controls. Nat Biotechnol 27: 66-75.

Sharov AA, Ko MS. 2009. Exhaustive search for over-represented DNA sequence motifs with CisFinder. DNA Res 16: 261-273.

Sive HL, Grainger RM, Harland RM. 2007. Dejellying Xenopus laevis embryos. Cold Spring Harb Protoc doi: 10.1101/pdb.prot4731.

Storey KG, Selleck MA, Stern CD. 1995. Neural induction and regionalisation by different subpopulations of cells in Hensen's node. Development 121: 417-428.

van Rooijen C, Simmini S, Bialecka M, Neijts R, van de Ven C, Beck F, Deschamps J. 2012. Evolutionarily conserved requirement of Cdx for post-occipital tissue emergence. Development 139: 2576-2583.

Woodland HR, Gurdon JB. 1968. The relative rates of synthesis of DNA, sRNA and rRNA in the endodermal region and other parts of Xenopus laevis embryos. J Embryol Exp Morphol 19: 363-385.

Zhang Y, Liu T, Meyer CA, Eeckhoute J, Johnson DS, Bernstein BE, Nusbaum C, Myers RM, Brown M, Li W, et al. 2008. Model-based analysis of ChIP-Seq (MACS). Genome Biol 9: R137. 


\title{
Investigating Physical Chromatin Associations Across the Xenopus Genome by Chromatin Immunoprecipitation
}

\author{
George E. Gentsch and James C. Smith
}

Cold Spring Harb Protoc; doi: 10.1101/pdb.prot080614

\begin{tabular}{rc}
$\begin{array}{r}\text { Email Alerting } \\
\text { Service }\end{array}$ & Receive free email alerts when new articles cite this article - click here. \\
\hline $\begin{array}{c}\text { Subject } \\
\text { Categories }\end{array}$ & $\begin{array}{c}\text { Browse articles on similar topics from Cold Spring Harbor Protocols. } \\
\text { DNA:Protein Interactions (74 articles) } \\
\text { Genome Analysis (191 articles) } \\
\text { Immunoprecipitation (75 articles) } \\
\text { Molecular Biology, general (1293 articles) } \\
\text { Xenopus (210 articles) }\end{array}$ \\
\hline
\end{tabular}

